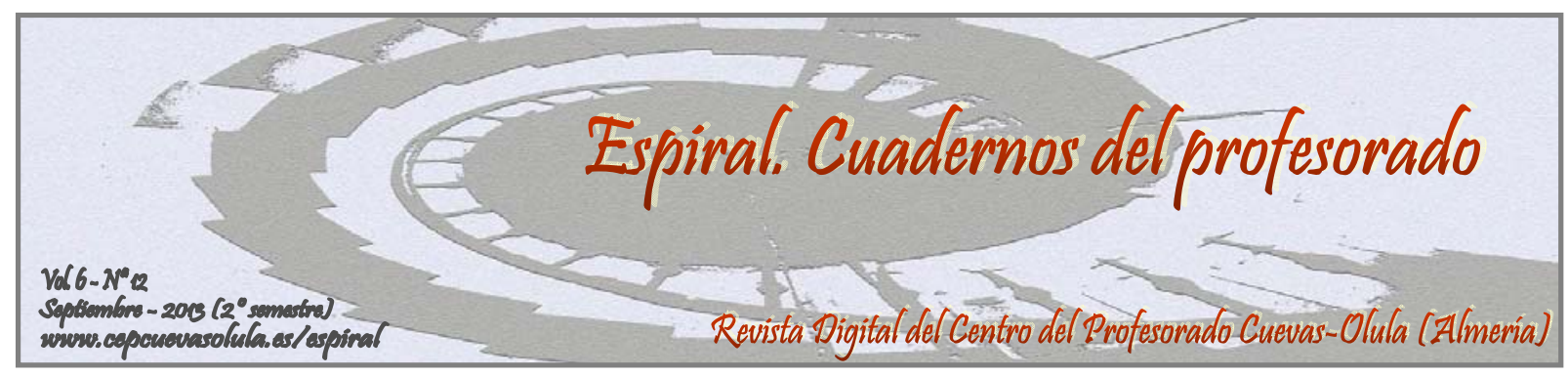

\title{
LOS ITINERARIOS DIDÁCTICOS: UN RECURSO INTERDISCIPLINAR Y VERTEBRADOR DEL CURRICULUM
}

\author{
DIDACTIC ITINERARIES: AN INTERDISCIPLINARY PROGRAMME \\ INTEGRATED IN THE CURRICULUM
}

\author{
Francisco López de Haro y José Antonio Segura Serrano
}

CEIP Nuestra Señora del Rosario, Guazamara, Cuevas del Almanzora, Almería, España

RESUMEN: El Programa de Itinerarios Didácticos de la Ecoescuela de Guazamara es una experiencia que se ha ido consolidando en los últimos cursos, formando ya parte del proyecto educativo de este centro. La coordinación del profesorado de varias materias ha hecho posible la integración en el mismo de la considerable propuesta de actividades de carácter interdisciplinar que exponemos en este trabajo, estructuradas, según el patrón temporal ya típico, en actividades previas a la salida, durante la misma y posteriores a ésta. Estas actividades, diseñadas teniendo en cuenta los objetivos y métodos de la Educación Ambiental, muestran como los itinerarios didácticos pueden convertirse en un valioso instrumento integrador y vertebrador del curriculum, motivador y muy útil para trabajar diferentes competencias básicas; así como para introducir, desarrollar y complementar una gran variedad de objetivos y contenidos de nuestras programaciones. Esto, unido a que se trata de una propuesta basada en la normativa educativa vigente, contribuye a superar la tradicional consideración de los itinerarios didácticos como un complemento al margen del curriculum. Los resultados de la evaluación sugieren que este tipo de experiencias son eficaces para alcanzar los objetivos planteados, mejorando, incluso, la valoración del entorno y la percepción del paisaje.

Palabras clave: itinerario didáctico, interdisciplinar, educación ambiental, currículum, entorno natural.

ABSTRACT: The Programme "Didactic itineraries of the Eco-school of Guazamara" is an experience that has been consolidated in recent years and it has been included in the educative project of the school of Guazamara. The coordination among teachers of different subjects has allowed us to integrate in the project a wide variety of interdisciplinary activities that are shown in this paper. These activities have been structured according to a temporary pattern which is typical in activities realised before departure, during the realisation of the route and after it. These activities have been designed taking into account the objectives and methods of the Environmental Education. They show how the didactic itineraries may become a valuable tool that give cohesion and integrate the curriculum, and how they are motivating and very useful so as to work with different basic competences. In addition, these activities are also very useful in order to introduce, develop and complement a great variety of objectives and contents from our didactic programmings. All these facts, together with the fact that it is a proposal based in the legislation currently in force, contribute to overcome the traditional consideration of the didactic itineraries as a complement aside the curriculum. The result of the evaluation suggests that this kind of experiences are effective to reach the goals proposed, even improving the appraisal of the environment and the perception of the landscape.

Key words: didactic itinerary, interdisciplinary, environmental education, curriculum, environment. 
López de Haro, F., y Segura Serrano, J. A. (2013). Los itinerarios didácticos: un recurso interdisciplinar y vertebrador del curriculum. Espiral. Cuadernos del Profesorado, 6(12), 15-31. Disponible en: http://www.cepcuevasolula.es/espiral

Fecha de recepción: 24/07/2012

Fecha de aceptación: 26/11/2012
Enviar correspondencia a: pacolodeharo@gmail.com

\section{1.- INTRODUCCIÓN}

Pino Quílez (1997) apunta que la Institución Libre de Enseñanza, la cual desarrolló su labor a finales del siglo XIX y principios del XX, ya señalaba que "La excursión a la Naturaleza es un trabajo que forma parte esencial de la clase misma, en vez de ser un complemento de esta”. Sin embargo, aún hoy, este tipo de experiencias sigue considerándose por muchísimos docentes poco menos que actividades "florero", que quedan bien en la programación, la “adornan”, pero que en realidad están al margen del curriculum. Para una gran parte del profesorado (aunque no lo reconozcan abiertamente) suponen un paréntesis que retrasa la programación. Este hecho, junto con otros factores (prevalencia del libro de texto, desconocimiento del entorno inmediato...), provoca una resistencia de gran parte del profesorado a implicarse en procesos sistemáticos que tengan como escenario el medio natural.

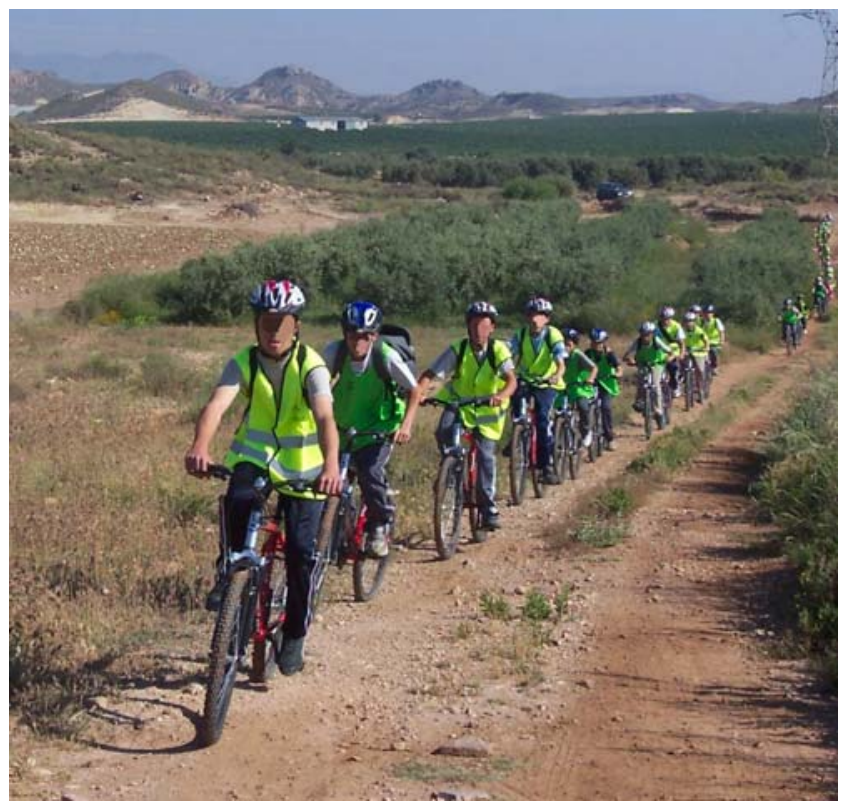

Figura 1. Utilizamos la bicicleta de montaña para acceder al comienzo de una de nuestras excursiones

Como indica su título, el principal objetivo de este artículo es mostrar que, contrariamente a lo señalado anteriormente, los itinerarios didácticos pueden convertirse en un valioso instrumento integrador y vertebrador del currículo, motivador y muy útil para trabajar diferentes competencias básicas, así como para introducir, desarrollar y complementar una gran variedad de objetivos y contenidos de nuestras programaciones. Es, asimismo, un recurso interdisciplinar, que integra con facilidad aspectos supuestamente pertenecientes a diferentes disciplinas, facilitando, por tanto, la tan demandada coordinación de docentes de distintas materias.

La primera justificación para integrar las salidas al entorno en la práctica escolar proviene de la propia normativa educativa, tanto nacional como autonómica, vigente en el lugar y en el momento en que se realizaron las actividades que se describen. La Ley Orgánica 2/2006, de 3 de mayo de Educación ( $L O E$ ) alude a la necesidad de trabajar el conocimiento del entorno, los valores ambientales, los hábitos saludables y el ejercicio físico en varios apartados sobre principios, fines y objetivos. También fija las competencias básicas que, como se irá viendo, son trabajadas de una u otra manera en este programa:

- La competencia en comunicación lingüística, imprescindible para interpretar todas las informaciones orales y escritas de las distintas actividades, así como para expresar sus dudas, opiniones..., responder por escrito a las cuestiones del cuaderno de campo y resto de actividades, así como alguna actividad creativa que se les plantea (Una de piratas).

- La competencia de razonamiento matemático, puesta en juego en el manejo de escalas, medidas de árboles, caudales... 
- La competencia en el conocimiento y la interacción con el medio físico, cuya relación con este programa resulta tan obvia que no requiere ninguna explicación complementaria.

- Competencia digital y tratamiento de la información, trabajada sobre todo en las búsquedas de información, el manejo de cartografía digital y sistemas de información geográfica.

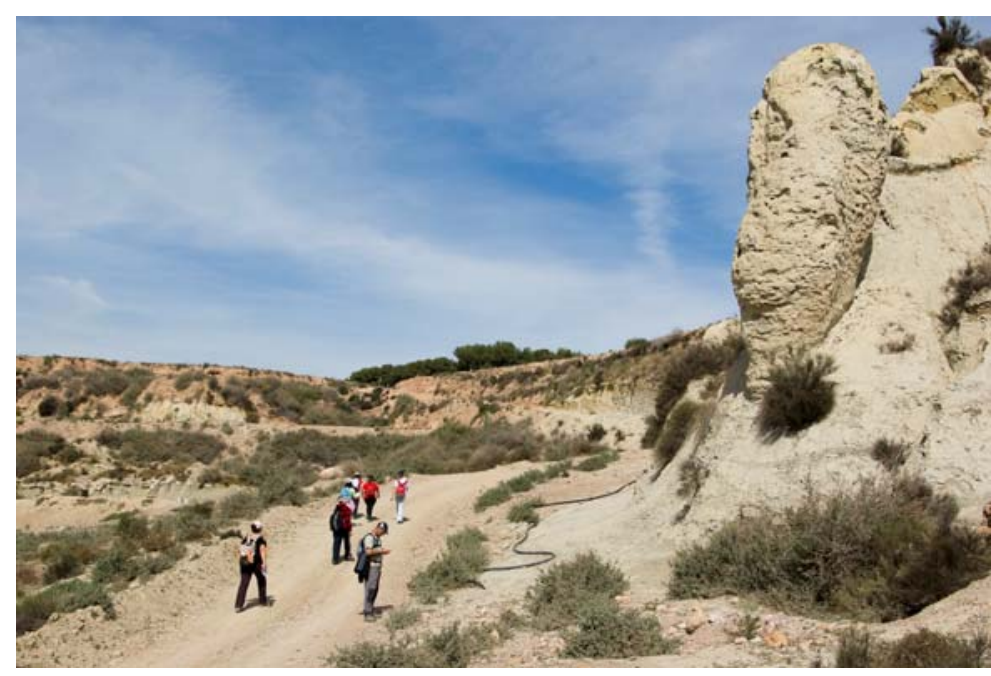

Figura 2. Los itinerarios transcurren por entornos semiáridos

- Competencia social y ciudadana, puesto que se facilita la comprensión del entorno en el que vivimos, necesaria para ejercer una ciudadanía democrática en defensa de los valores ambientales.

- Competencia cultural y artística, a partir de la puesta en valor de las manifestaciones culturales y etnográficas que son observadas en los itinerarios.

- Competencia y actitudes para seguir aprendiendo de forma autónoma, favorecida por la metodología utilizada y por los instrumentos de aprendizaje a los que el alumnado tiene acceso.

- Competencia para la autonomía e iniciativa personal, puesta en juego sobre todo en las actividades de defensa y mejora del entorno, propuestas por el propio alumnado. También se proporciona al alumnado instrumentos para planificar sus propias excursiones y alternativas de ocio.

El Real Decreto 1631/2006, de 29 de diciembre, por el que se establecen las enseñanzas mínimas correspondientes a la Educación Secundaria Obligatoria señala como objetivo "Concebir el conocimiento científico como un saber integrado que se estructura en distintas disciplinas, así como conocer y aplicar los métodos para identificar los problemas en los diversos campos del conocimiento y de la experiencia”, en clara sintonía con nuestra propuesta. Este mismo decreto distribuye los contenidos en niveles y bloques temáticos, de los cuales se trabajan de forma directa en este programa los siguientes:

- Educación Física

- $\quad$ Actividades en el medio natural $\left(1^{\circ} \mathrm{y}\right.$ $2^{\circ}$ de ESO)

- Ciencias Naturales

- $\quad$ Los Seres Vivos y la diversidad (1 ${ }^{\circ}$ de ESO)

- $\quad$ La geosfera $\left(1^{\circ}\right)$

- $\quad$ El medio ambiente natural $\left(2^{\circ}\right)$

- Transformaciones geológicas debidas a la energía interna $\left(2^{\circ}\right)$

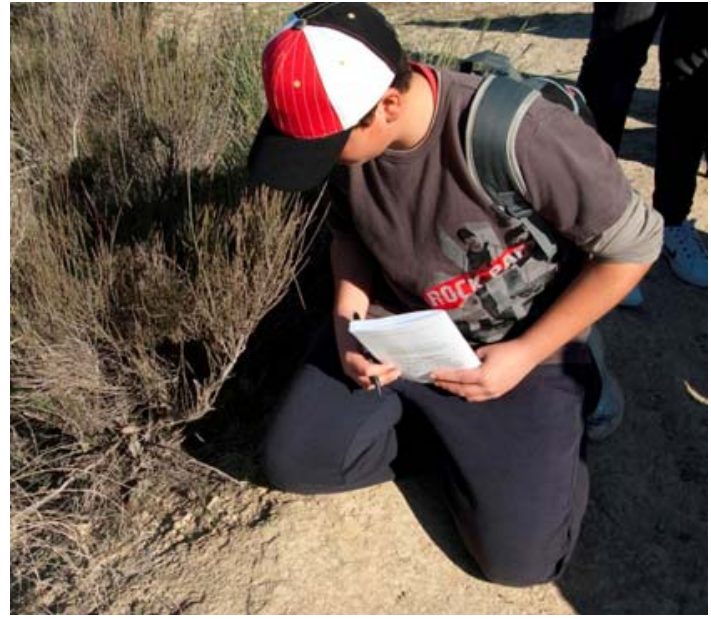

Figura 3.

El cuaderno de campo es un instrumento fundamental 
La Ley 17/2007, de 10 de diciembre, de Educación de Andalucía (LEA), por su parte, también alude en diversos apartados a la necesidad de hábitos saludables, respeto al medio ambiente, visión interdisciplinar... Y en el Artículo 40 señala que "El currículo deberá contemplar la presencia de contenidos y de actividades relacionadas con el medio natural, la historia, la cultura y otros hechos diferenciadores de Andalucía, para que sean conocidos, valorados y respetados como patrimonio propio y en el marco de la cultura española y universal”. Su desarrollo posterior en la Orden de 10 de agosto de 2007, por la que se desarrolla el currículo correspondiente a la Educación Secundaria Obligatoria en Andalucía, fija como núcleos temáticos:

- Ciencias de la Naturaleza

- El paisaje natural andaluz

- La biodiversidad en Andalucía

- El patrimonio natural andaluz

- El uso responsable de los recursos naturales

- Ciencias Sociales

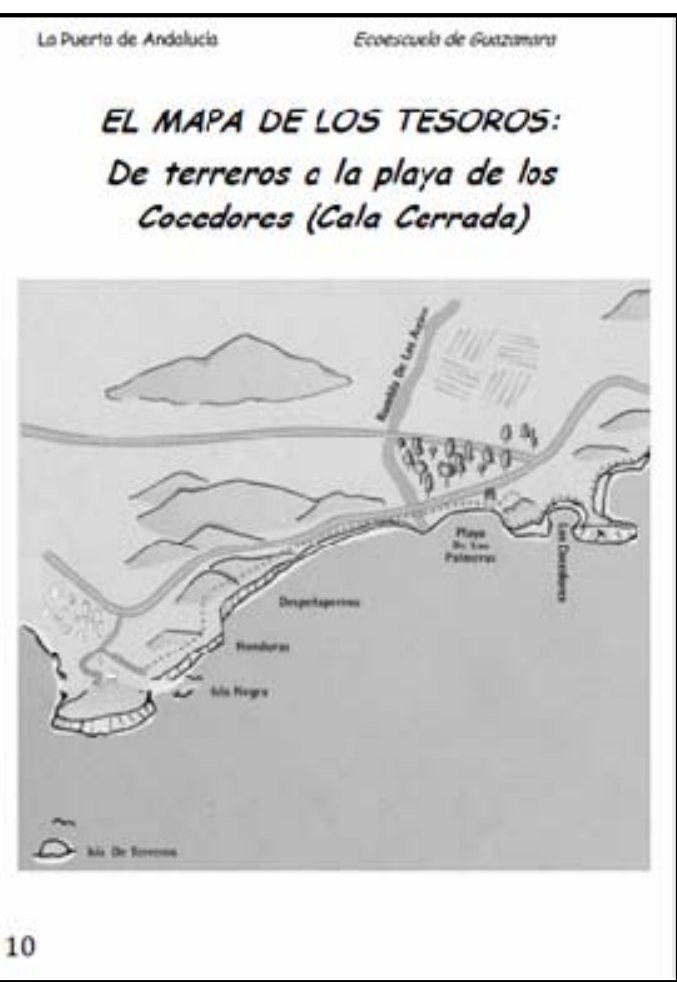

Figura 4. Croquis intuitivo

- La construcción histórica, social y cultural de Andalucía

- El patrimonio cultural andaluz

- El uso responsable de los recursos

- Tradición y modernización en el medio rural andaluz

- Ocio y turismo en Andalucía

- Participación social y política

Tras este repaso a la legislación educativa, no sólo se justifica la posibilidad de incluir en nuestras programaciones salidas al entorno inmediato, sino que parece muy difícil cumplir la citada normativa sin esta inclusión.

La propuesta educativa que aquí presentamos se enmarca dentro de la Educación Ambiental (en adelante EA). Pero aún hoy, 35 años después de la Conferencia de Tbilisi (1977) hay diferentes concepciones "entre las que predomina la heterogeneidad y el debate; la diversidad de paradigmas teóricos, de estrategias de actuación, de practicantes y escenarios (García Díaz, 2002)”. No pretendemos entrar en disquisiciones al respecto, únicamente señalar que en el diseño y ejecución del programa de actividades aquí descrito se ha intentado participar a la vez de la concepción pedagogista y ambientalista de la EA, es decir, se ha pretendido educar en el

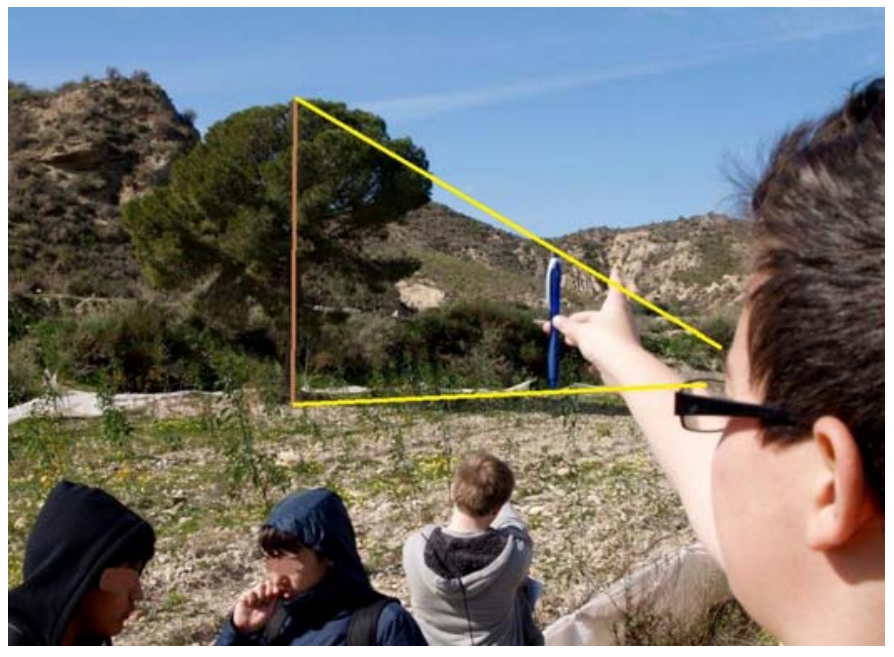

Figura 5. Midiendo la altura de un árbol con un bolígrafo 
medio, sobre el medio y para el medio. Somos conscientes de que "el hecho de trabajar a fondo y científicamente los contenidos del medio no supone necesariamente que se hace EA" (Jiménez y Laliena, 1992). En este sentido se han conectado con este programa otras actividades de la Ecoescuela (reforestación, vivero, divulgación y medidas de protección de la biodiversidad...), que implican un compromiso proambiental que se traduce en la ejecución de actuaciones concretas. Si bien nos hemos centrado sobre todo en la integración y vertebración de aspectos curriculares, los objetivos y métodos de la EA han impregnado todas las fases del programa. Se ha pretendido que el alumnado adquiera las herramientas y conocimientos necesarios para conocer y comprender su entorno, lo que le posibilitará analizar críticamente la realidad y actuar en consecuencia. Por otro lado hay investigaciones que demuestran que el acercamiento al entorno con una metodología "experimental" mejora, además de los conocimientos conceptuales, las actitudes y la intención de conducta proambientales (Pérez Casas, 2005).

Salir al campo implica necesariamente realizar ejercicio, y además uno de los más sanos, por lo que además de lo dicho, es una excelente oportunidad para trabajar aspectos relacionados con el ejercicio físico y la salud, adquiriendo la materia de Educación Física un especial protagonismo. Aunque “...prácticamente todos los contenidos propios de la Educación Física escolar son susceptibles de trabajarse en el entorno natural y en general con sustanciosas ventajas” (Pino Quílez, 1997), es el senderismo la modalidad que mejor se adecua a nuestros objetivos. "Las actividades físicas en el medio natural (AFMN) dentro del contexto escolar, y más concretamente el senderismo, constituyen un poderoso instrumento educativo y uno de los medios más eficaces para el desarrollo integral del alumno/a.” (Gómez López, 2008). La práctica de esta modalidad deportiva supone, además, una alternativa de ocio sana que "satisface la necesidad de riesgo y aventura del alumnado que mal orientada conduce a conductas de carácter antisocial, gamberrismo, drogas...” (Pino Quílez, 1997). Por otra parte las posibilidades de que el alumnado practique senderismo por su cuenta son mayores que para otras AFMN, puesto que "es, sin lugar a duda, la manera más básica y sencilla de practicar actividades físicas en la naturaleza y la más accesible para todos/as” (Casterad, Guillén y Lapetra, 2000).

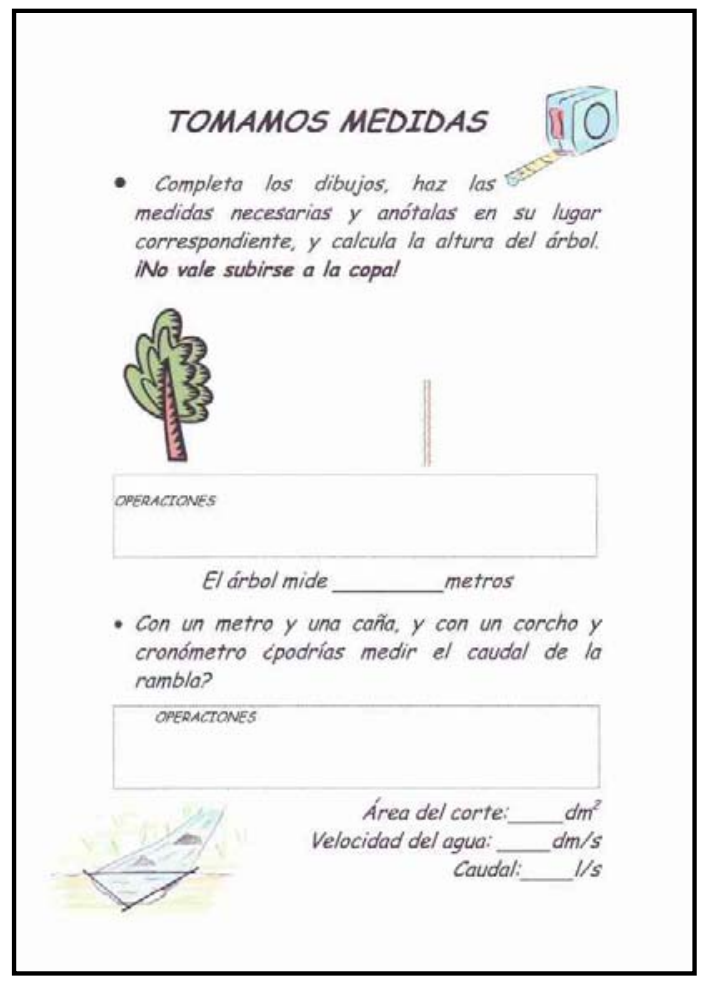

Figura 6. Matemáticas en el medio natural

Otra actividad deportiva practicada por el alumnado será la bicicleta de montaña, que nos permite el acceso a una de las zonas visitadas, en un itinerario combinado "ciclosenderista" (Figura 1). En este sentido, a las dificultades, mencionadas al principio de este capítulo, para la realización de salidas al entorno, se suele unir la necesidad de largos desplazamientos a espacios naturales que tengan "suficiente" interés. Todos los itinerarios de nuestra propuesta son por el entorno inmediato al centro. Sólo utilizamos el autobús para uno de ellos, y el desplazamiento es de $18 \mathrm{~km}$. Evidentemente, el hecho de situarse el centro en un entorno rural ayuda, pero en cualquier caso creemos que es fundamental que el alumnado conozca su entorno inmediato, en el que siempre se pueden encontrar suficientes elementos de interés. El Colegio Público de Infantil y Primaria (C. E. I. P.) Ntra. Sra. del Rosario se encuentra situado en el Levante Almeriense, en un entorno semiárido considerado de poco interés natural por la población en general (Fig. 2). En el diseño del programa siempre tuvimos en cuenta esta cuestión, porque, además, uno de los nuestros objetivos es que se valore la biodiversidad, 
rareza, singularidad e incluso valor estético de estos parajes áridos y semiáridos, que los hace únicos en el continente europeo, y los sitúa en un lugar destacado de nuestro patrimonio natural.

En el último curso, algunas de las cuestiones científicas y matemáticas (escalas, biodiversidad, erosión) que han suscitado el desarrollo del programa han sido abordadas mediante la metodología IBL (Inquiry-Based Learning) de aprendizaje por investigación, entendida como "un proceso intencional en el que se diagnostican problemas, se analizan experimentos críticamente, se distinguen diferentes alternativas, se planifican investigaciones, se formulan conjeturas, se busca información, se construyen modelos, se debate entre iguales, y se llega a argumentos coherentes" ${ }^{1}$.

Por último, señalar que el alumnado suele participar en este tipo de actividades "con un grado de motivación intrínseca muy alto” (Aguado, 2001; citado por Beas, Rodríguez y Martínez, 2009), motivación de la que se puede sacar una gran rentabilidad educativa.

\section{2.- CONTEXTO}

Todo lo descrito en este artículo ha sido desarrollado en el C. E. I. P. Ntra. Sra. del Rosario, situado en Guazamara, una pedanía perteneciente a Cuevas del Almanzora en la provincia de Almería. En pleno sureste semiárido, el paisaje es un mosaico

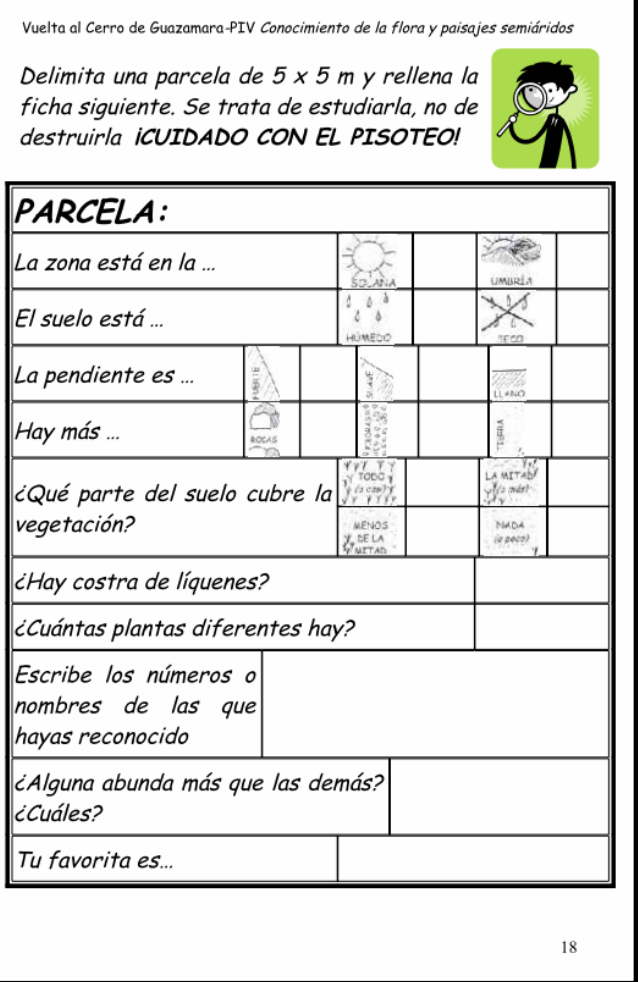

Figura 7. Parcelas de vegetación de "badlands", campos de cultivo, monte bajo y bosquecillos de pinos en las sierras calizas que delimitan la zona por el este y el oeste: la sierra de los Pinos y la de Almagro. La red hidrográfica está constituida por ramblas, siendo las más importantes la de Guazamara y la de Canalejas, que se abre paso hacia el mar, situado a unos $8 \mathrm{~km}$. hacia el sur en línea recta.

Domina el hábitat disperso en un entorno rural salpicado de cortijadas. Guazamara es el principal núcleo de población, pero al colegio asisten desde otros núcleos cercanos de menor entidad (Los Guiraos, El Largo, Grima...). La población total de estas localidades es de unos 1200 habitantes, que basan su economía principalmente en la agricultura y la ganadería.

El centro consta de 10 unidades (11 en algunos cursos), en las que se imparten Educación Infantil, Primaria, $1^{\circ}$ y $2^{\circ}$ de ESO, siendo en ESO donde se desarrolla fundamentalmente el programa que describimos. La ratio media es de unos 10 alumnos/as por clase. Esto último facilita mucho las actividades en el medio natural, pero también aumenta los costes cuando estas implican desplazamientos en autobús, por lo que es necesario, en este caso, planificar las actividades para varios niveles.

Una de las señas de identidad de este centro es su pertenencia a la Red Andaluza de Ecoescuelas, participando en este programa, de ámbito internacional, desde el curso 1999-2000 hasta la actualidad, y habiendo obtenido el galardón del mismo, la bandera verde, en tres ocasiones consecutivas.

El colegio dispone de una especie de minijardín botánico o arboreto, donde conviven especies plantadas y silvestres, pero todas autóctonas, en un espacio atravesado por sendas acondicionadas y con presencia de una charca. Lo hemos llamado “Tortujardín”, por ser éste el hábitat de la Tortuga

\footnotetext{
${ }^{1}$ Extraído de de la Guía para formadores de profesores del Proyecto Primas (Promoting Inquiry in Mathematics and Science Education Across Europe), donde se cita como basado en Linn, Bell and Davis (2004).
} 
Mora, y la "Tortu”, la mascota de la Ecoescuela de Guazamara. Este espacio, y su correspondiente guía de plantas, "Las cuarenta principales", suponen un recurso complementario al propio entorno. Otra característica que condiciona el programa es la movilidad del profesorado, cambiando, por ejemplo, el de Ciencias Sociales cada curso, lo cual ha dificultado mucho la coordinación.

\section{3.- ORIGEN DE LA EXPERIENCIA}

El entorno es uno de los temas básicos del Programa de Ecoescuelas, por lo que su estudio y conservación ha sido, y es, una pieza básica de la actividad del centro. Esta actividad ha estado condicionada por la ubicación del colegio en la zona más árida de Europa, y el hecho de que la desertificación sea uno de los problemas ambientales más importantes de la comarca, hasta el punto de que las primeras actividades de EA que realizó el centro, incluso antes de ser ecoescuela, trataban estas temáticas (reforestación, vivero escolar, vegetación autóctona...).

En este sentido, la cercanía de una zona de "badlands", ofrecía al profesor de Ciencias Naturales la posibilidad de estudiar los procesos erosivos sobre el terreno. El profesor de Educación Física, por su parte, vio en estas excursiones una oportunidad para desarrollar sus objetivos relacionados con las AFMN. De forma que estas excursiones empezaron a realizarse de manera conjunta, integrándolas en las programaciones didácticas, elaborando cuadernos de campo... A esto siguió la

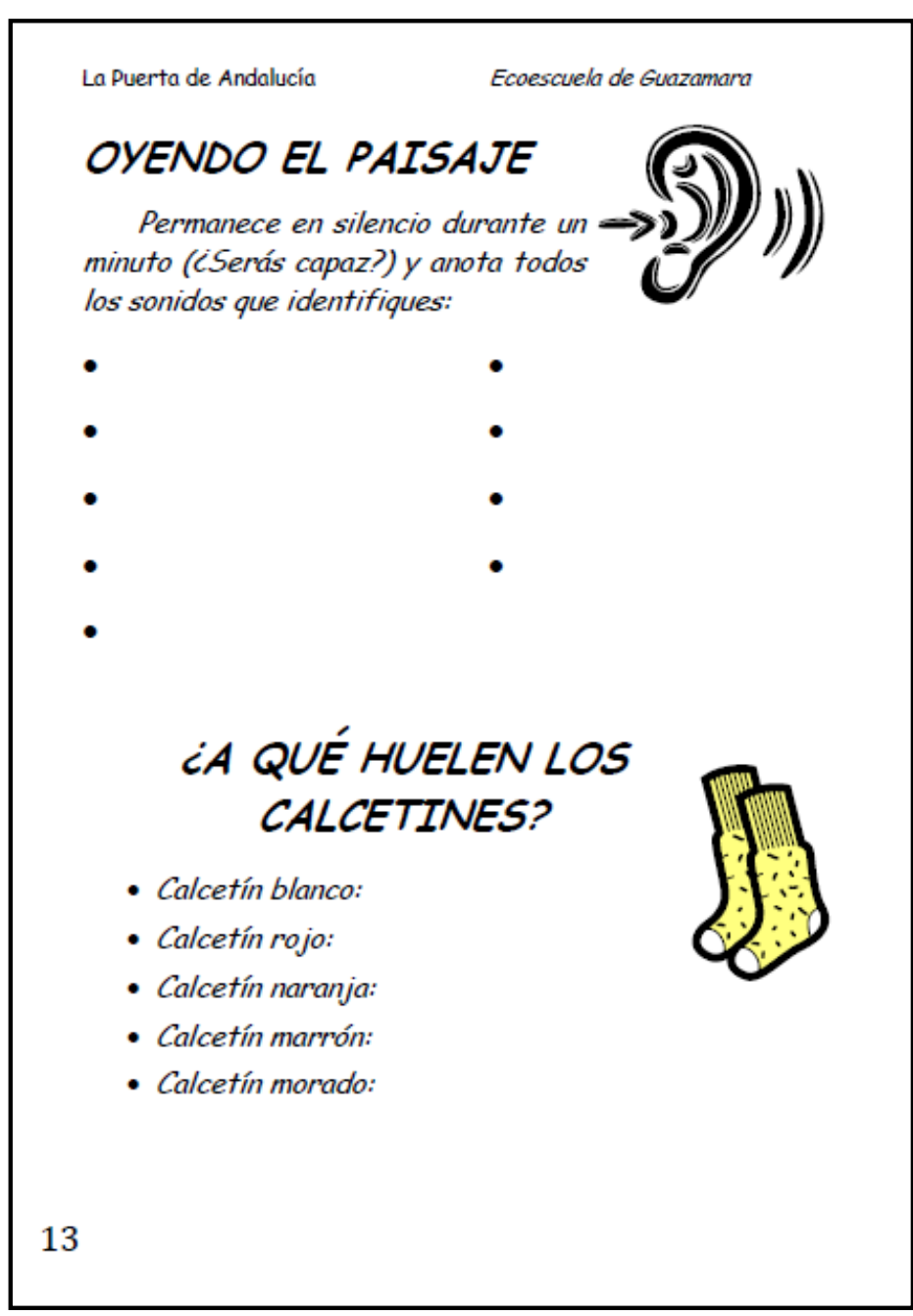
planificación conjunta de estancias en Aulas de Naturaleza y la introducción de actividades de otras materias impartidas por los mismos profesores: Matemáticas y Tecnología. Más tarde el colegio ganó el certamen "Pon verde tu aula", recibiendo como premio una dotación de bicicletas de montaña, lo que ofreció la posibilidad de iniciar al alumnado en la práctica de este deporte al tiempo que se podían hacer aproximaciones a otras zonas más alejadas del colegio para realizar excursiones.

Durante diez cursos se han ido incorporando nuevas actividades, matizando, o eliminado, otras. Se hizo pues necesario organizar todo esto en un programa plurianual, completo y coherente, pero sobre todo viable, que seguimos curso tras curso con la flexibilidad necesaria para adaptarse a las circunstancias y a las oportunidades que se van presentando (Tabla 1).

\section{4.- OBJETIVOS}

- Contextualizar el curriculum y elaborar materiales para su desarrollo a partir del entorno inmediato.

- Abordar el estudio del medio desde una perspectiva interdisciplinar y/o multidisciplinar. 
- Superar la prevalencia del libro de texto sobre cualquier otra forma de enseñanza aprendizaje, y de las ejemplificaciones lejanas y ajenas, mediante la observación sobre el terreno de los principales elementos de los paisajes y ecosistemas del entorno.

- Divulgar y reconocer los valores naturales, históricos y etnográficos próximos como parte de nuestro patrimonio.

- Fomentar la práctica de actividades físicas en la naturaleza como hábito saludable, alternativa de ocio sano y como una manera de conocer y entender mejor su medio.

- Iniciar al alumnado en las técnicas básicas de orientación e interpretación de mapas.

- Desarrollar en el alumnado las capacidades para analizar los problemas de conservación de nuestro patrimonio natural y cultural e implicarse en actuaciones para paliarlos.

Tabla 1

Esquena básico del Programa de Actividades en el Medio Natural

\begin{tabular}{|c|c|c|c|}
\hline \multicolumn{4}{|c|}{$\begin{array}{c}\text { PROGRAMA DE ACTIVIDADES EN EL MEDIO NATURAL DE LA ECOESCUELA DE } \\
\text { GUAZAMARA } \\
\text {-Esquema Básico- }\end{array}$} \\
\hline Nivel & Actividad & Educación Física & Ciencias Naturales \\
\hline \multirow[b]{2}{*}{$1^{\mathrm{o}}$} & $\begin{array}{l}\text {-Excursión ciclosenderista } \\
\text { (aproximación en BTT) al } \\
\text { Cerro de los Pinos. }\end{array}$ & $\begin{array}{l}\text {-Iniciación a la bicicleta de } \\
\text { montaña (BTT). }\end{array}$ & $\begin{array}{l}\text { - Biodiversidad. } \\
\text { - Ecosistemas de monte } \\
\text { mediterráneo }\end{array}$ \\
\hline & $\begin{array}{l}\text { - La Puerta de Andalucía: } \\
\text { itinerario por la costa de } \\
\text { Terreros. (conjunta ESO cada } 2 \\
\text { cursos). }\end{array}$ & $\begin{array}{l}\text { - Iniciación senderismo. } \\
\text { - Iniciación orientación }\end{array}$ & $\begin{array}{l}\text { - Clasif. seres vivos. } \\
\text { - Materiales y procesos } \\
\text { geológicos } \\
\text { - Ecosistemas costeros. }\end{array}$ \\
\hline & $\begin{array}{l}\text { - Visita al karst de Yesos de } \\
\text { Sorbas. (conjunta ESO, } 5^{\circ} \text { Y } 6^{\circ} \\
\text { cada } 4 \text { cursos). }\end{array}$ & -Iniciación a la Espeleología & $\begin{array}{l}\text { - Procesos cársticos. } \\
\text {-Espacios naturales }\end{array}$ \\
\hline \multirow{3}{*}{$2^{\circ}$} & $\begin{array}{l}\text { - Estancia en aula de } \\
\text { naturaleza. (conjunta ESO cada } \\
2 \text { cursos) }\end{array}$ & $\begin{array}{l}\text {-Iniciación a las carreras de } \\
\text { orientación }\end{array}$ & -Ecosistemas de montaña \\
\hline & \multirow{2}{*}{$\begin{array}{l}\text { - Vuelta al Cerro de } \\
\text { Guazamara: itinerario didáctico } \\
\text { a pie. }\end{array}$} & - Senderismo & - Erosión y desertización. \\
\hline & & & \\
\hline
\end{tabular}

\section{5.- DESCRIPCIÓN DE ACTIVIDADES Y MATERIALES ELABORADOS}

Todas las actividades de este programa giran en torno a las salidas al campo expuestas en la tabla 1. Las estancias en Aulas de Naturaleza se realizan en el marco del Programa de Rutas Educativas por Andalucía; la visita al Karst de Yesos de Sorbas, se realizó la última vez aprovechando la convocatoria del Programa La Naturaleza y Tú; y la excursión a "La Puerta de Andalucía” (zona costera entre el límite regional y San Juan de los Terreros) se coordinó también el último curso con el Programa Cuidemos la Costa. Todos estos programas se integran en el Programa Aldea de la Junta de Andalucía, por lo que los costes para el alumnado son mínimos. Pero en esta descripción nos vamos a centrar en las actividades propias solo de nuestro Centro, aunque para las demás haya habido siempre una buena coordinación entre los responsables de cada programa y el profesorado participante, que hemos aportado nuestras propuestas. 


\section{Tabla 2}

Actividades previas a las salidas

\begin{tabular}{ccc}
\hline ACTIVIDADES PREVIAS & Nivel \\
\hline
\end{tabular}

\section{Educación Física}

Senderismo

- Trabajo en clase sobre nociones elementales de senderismo: tipos de sendero, ropa, ali- $\quad X \quad X$ mentación...

- Trabajo en las páginas del cuaderno de campo Recomendaciones y Me tengo que llevar. X X

Preparamos la excursión: trabajo sobre la ficha técnica del itinerario, para ello será necesario $\quad$ X $\quad$ X trabajar las escalas.

BTT

- Preparación de las bicicletas: rudimentos de mecánica y mantenimiento de BTT.

- Práctica de conducción: uso de frenos, cambios, posición sobre la bici según terreno...

\section{Matemáticas}

Escalas

- Construcción de un curvímetro casero con un hilo, ayudándose de la cuadrícula UTM como escala gráfica, y medición de la longitud del recorrido.

- Resolución de problemas: determinación de la escala numérica de la fotocopia ampliada del mapa y medición del recorrido haciendo los cálculos correspondientes.

Mapas

- El mapa de los tesoros: interpretación de croquis intuitivos (Fig. 4).

- Interpretación de mapas topográficos, identificando ramblas, casas, caminos, carreteras...

- Trabajo con curvas de nivel: realización de un corte topográfico del Cerro de Guazamara, localización de acantilados, picos, collados...

\section{Ciencias Naturales}

El_universo

- Observación nocturna del firmamento: localización de la Estrella Polar y orientación.

Transformaciones geológicas.

- Planteamiento con metodología IBL para que el alumnado diseñe un experimento para comprobar en el campo la influencia de las plantas en la protección de suelos (Construcción de un erosionómetro en el patio).

Biodiversidad

- $\quad$ Diseño por el alumnado (metodología IBL) de un procedimiento para valorar la biodiver- $\quad X$ sidad de diferentes zonas (parcelas de muestreo...).

Ecosistema

- Juego de simulación o de roles sobre una actuación humana muy impactante sobre la zona a visitar (urbanización, instalación industrial...), que suele acabar con la propuesta de hacer un estudio sobre sus valores naturales (metodología de proyectos).

Las salidas al campo en las cuales se basan estas actividades son:

- Vuelta al Cerro de Guazamara por la Rambla de Las Gachas

- La Puerta de Andalucía: itinerario por la costa de Terreros

- Excursión ciclosenderista (aproximación en BTT) al Cerro de los Pinos

Con ellas abarcamos todos los ambientes representativos de la comarca: bosque de pinos, matorral mediterráneo, monte bajo, badlands, cultivos, ramblas y costa. 
Actividades realizadas durante las salidas

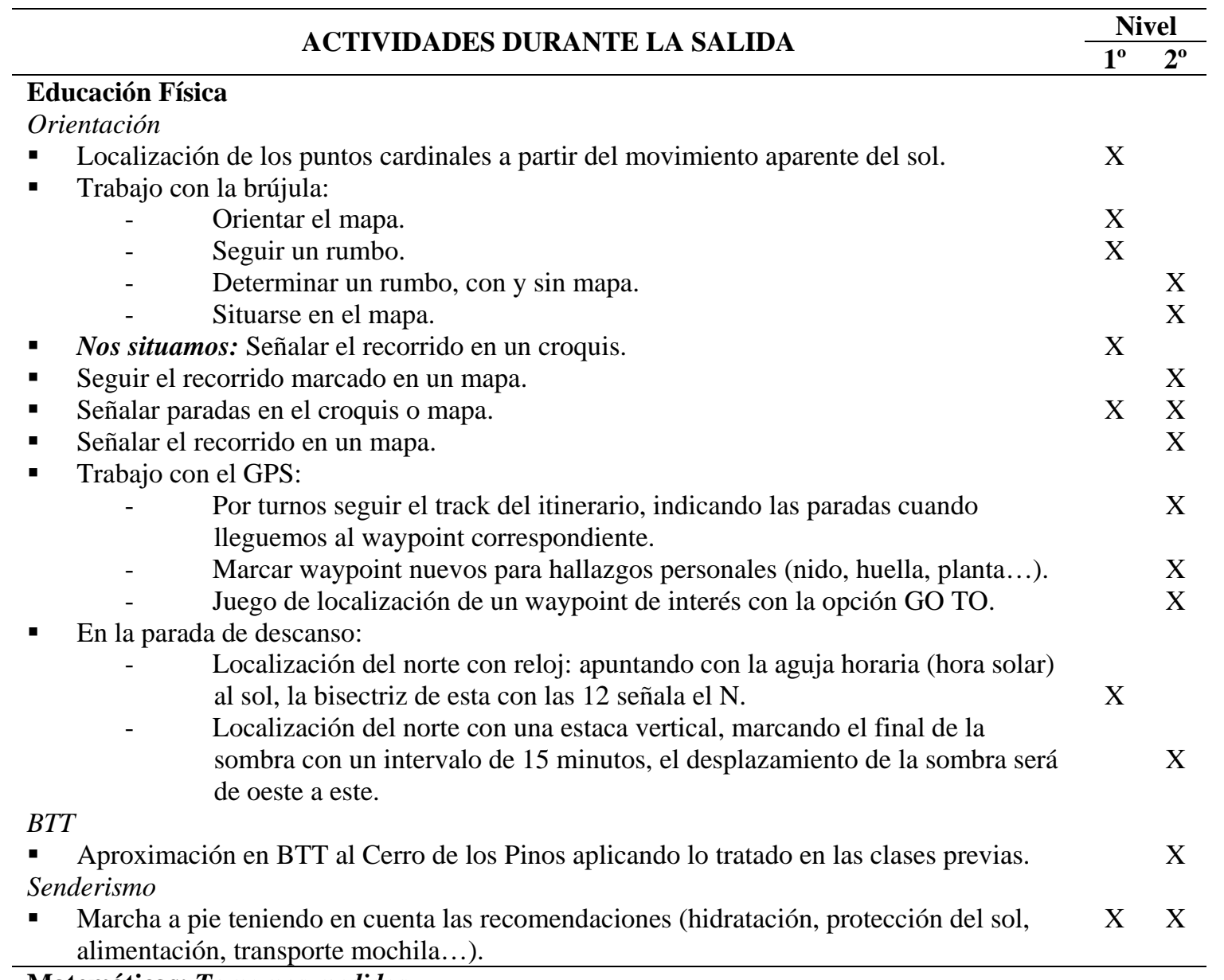

Matemáticas: Tomamos medidas.

- Medidas de la altura de un árbol (Fig. 5):

- $\quad$ Estirando el brazo con un lápiz en la mano, desplazarnos hasta que visualmente la altura del árbol coincida con el lápiz, proyectar esta longitud en el suelo y medir.

- $\quad$ Mediante semejanza de triángulos, midiendo la longitud de una estaca vertical y las de las sombras de ésta y el árbol.

- Cálculo del caudal de la rambla (Fig. 6).

\section{Ciencias Naturales}

Geosfera

- Busca los tesoros: observación de diferentes materiales geológicos, sedimentarios, metamórficos y volcánicos, situándolos en el mapa.

- Geología en miniatura: observación de fenómenos geológicos: fracturas, pliegues, afloramientos volcánicos, fósiles... situándolos en el mapa.

- Localización sobre el terreno de mecanismos de erosión y evolución de laderas.

- Experimentos de permeabilidad de suelos y medida de la erosión.

- Observación de los horizontes del suelo sobre un talud y dibujo en el cuaderno de campo.

- Observación de actuaciones humanas que favorecen o frenan la erosión y la desertización.

Biodiversidad y Ecosistemas

- Estudio de parcelas de vegetación: factores físicos, $n^{\circ}$ de especies, cobertura...(Figura 7) $\quad X \quad X$

- ¿A qué huelen los calcetines?: identificación de plantas aromáticas por su olor (Fig. 8). $\quad$ X $\quad X$

- Oyendo el paisaje: guardar silencio un minuto y anotar los sonidos escuchados. $\quad$ X X

- Observación e identificación de flora y fauna en las paradas, aprovechado encuentros oportunos o a través de actividades lúdicas como: 


\begin{tabular}{|c|c|c|c|}
\hline- & $\begin{array}{l}\text { En la playa de todo encontrarás: juego de adivinanzas sobre seres vivos } \\
\text { costeros. }\end{array}$ & $\mathrm{X}$ & $X$ \\
\hline - & La Isla Negra y sus misterios: Posidonia oceánica y aves costeras. & $\mathrm{X}$ & $\mathrm{X}$ \\
\hline - & l. & $\mathrm{X}$ & \\
\hline - & $\begin{array}{l}\text { Siguiendo el rumbo lo encontrarás: localización de elementos naturales a } \\
\text { partir de un rumbo y una distancia (brújula) o un waypoint (GPS). }\end{array}$ & & $\mathrm{X}$ \\
\hline - & Buscamos pistas y $A_{t}$ & $\mathrm{X}$ & $\mathrm{X}$ \\
\hline - & $\begin{array}{l}\text { Se busca (Fig. 9): hacer de detectives y encontrar especies a partir de unas } \\
\text { pistas. }\end{array}$ & $X$ & \\
\hline- & & & $X$ \\
\hline - & $\begin{array}{l}\text { El ecosistema del azufaifo: observación de especies en torno a esta planta } \\
\text { refugio. }\end{array}$ & & $\mathrm{X}$ \\
\hline & $\begin{array}{l}\text { Cada especie en su sitio: rotular símbolos de las especies, situándolas en su } \\
\text { hábitat sobre una foto }\end{array}$ & $X$ & $\mathrm{X}$ \\
\hline \multirow{2}{*}{\multicolumn{2}{|c|}{$\begin{array}{l}\text { - Observación de las características de los biotopos, ejemplos de adaptaciones a ellos de } \\
\text { los seres vivos y relaciones entre éstos. } \\
\text { Identificación sobre el terreno de actuaciones humanas positivas y negativas para la bio- } \\
\text { diversidad y los ecosistemas, anotándolos en el cuaderno, y realizando la actividad }\end{array}$}} & & $X$ \\
\hline & & $\mathrm{X}$ & $\mathrm{X}$ \\
\hline \multirow{6}{*}{\multicolumn{2}{|c|}{$\begin{array}{l}\text { Ciencias Sociales } \\
\text { - Oteando el horizonte: observación sobre el terreno de accidentes geográficos a pequeña } \\
\text { escala: delta, albufera, duna, islas, bahía, cabos, sierras, depresiones... } \\
\text { - Análisis sobre el terreno de diferentes formas de aprovechamiento del agua en diferentes } \\
\text { épocas: boqueras, bancales, sangradores, norias de tiro y aljibe (Figura 10). } \\
\text { - Ejemplos de adaptación del hombre a su medio y uso de éste como base de las activida- } \\
\text { des económicas: cocedores de esparto (Qué se cuece aqui), “terreros” (viviendas troglo- } \\
\text { ditas)... } \\
\text { - Visita a la batería de costa de San Juan de los Terreros y estudio de su función tras la ex- } \\
\text { pulsión de los musulmanes. } \\
\text { Actividades del cuaderno encaminadas a conocer los monumentos locales, la arquitectura } \\
\text { popular y colonial, leyendas... }\end{array}$}} & & \\
\hline & & $\mathrm{X}$ & $\mathrm{X}$ \\
\hline & & $X$ & $X$ \\
\hline & & $\mathrm{X}$ & $\mathrm{X}$ \\
\hline & & $\mathrm{X}$ & $\mathrm{X}$ \\
\hline & & $X$ & $X$ \\
\hline
\end{tabular}

Las tres salidas están perfectamente documentadas, habiéndose preparado:

- Una descripción detallada del itinerario y sus paradas, además de su ficha técnica.

- Plano topográfico de la zona por donde discurre, el track de su recorrido y waypoint de las paradas.

- Cuaderno de campo del alumnado (Fig. 3), que se ha convertido sin duda en el instrumento más valioso. Vertebra y da sentido a todas las actividades, supone una guía para la temporalización de las tareas, un recurso imprescindible para la puesta en común final, tras la cual se convierte en una fuente de consulta permanente en el desarrollo de los diferentes contenidos. Durante las salidas, fija la atención del alumnado, al tener que tomar nota de cada parada, situarla en el mapa o croquis y realizar las tareas que propone. Incluso se ha utilizado en la evaluación, en la prueba escrita sobre los ecosistemas.

Todas las actividades se estructuran según el patrón temporal, ya típico en los itinerarios didácticos, en actividades previas a la salida (Tabla 2), durante la salida (Tabla 3) y posteriores a la salida (Tabla 4). En estas últimas se incluyen tanto las inmediatamente posteriores como las diferidas en el tiempo, utilizadas para el desarrollo de unidades didácticas de diferentes áreas. Esta relación de actividades es un compendio de todo lo realizado en la ejecución del programa que estamos describiendo, que hay que entender como una propuesta flexible. Cada curso hemos tenido que adaptarnos al alumnado, calendarios y circunstancias como el aprovechamiento de diversas oportunidades y convocatorias, aunque, finalmente, el trabajo realizado suele aproximarse mucho a esta propuesta. 
Tabla 4

Actividades posteriores a las salidas

\begin{tabular}{|c|c|c|}
\hline \multirow{2}{*}{ ACTIVIDADES POSTERIORES } & \multicolumn{2}{|c|}{ Nivel } \\
\hline & $\mathbf{1}^{\mathbf{0}}$ & $2^{\circ}$ \\
\hline $\begin{array}{l}\text { - Puesta en común de las anotaciones del cuaderno de campo, completando los apartados } \\
\text { que no dio tiempo a hacer sobre el terreno. } \\
\text { - Una de Piratas: completar una historia de piratas que arriban a Terreros (Lengua). }\end{array}$ & $\mathrm{X}$ & $\mathrm{X}$ \\
\hline $\begin{array}{l}\text { Educación Física } \\
\text { - Comprobación del recorrido y las paradas: descarga el track y los waypoint de las para- } \\
\text { das del recorrido con fotos vinculadas, ayudándose del programa Ozi Explorer, y recrear } \\
\text { el track proyectando la imagen con un videoproyector. }\end{array}$ & & $\mathrm{X}$ \\
\hline
\end{tabular}

Ciencias Naturales

Geosfera

- Proyección de fotos sobre rocas sedimentarias, metamórficas y magmáticas, así como X ejemplos de minerales observados en la salida a Terreros.

Transformaciones Geológicas

- Utilización de lo observado en Terreros para desarrollar los procesos volcánicos.

- Repaso de las muestras y fotografías de materiales volcánicos observados en la salida: lapilli, cenizas y bombas volcánicas.

- Referencias a ejemplos de formación del relieve observados en el entorno: paisaje tabular, plegamientos, fallas, deltas, cabos, albuferas, dunas...

- La desertificación: proyección y comentario de un Diaporama de elaboración propia.

La biodiversidad

- $\quad$ Análisis del número de especies en las parcelas para comparar la biodiversidad de dife- $\quad \mathrm{X}$ rentes ambientes y afianzar el concepto.

- Búsqueda de información sobre los fósiles observados e introducción al concepto de evo- $\quad \mathrm{X}$ lución.

- A partir de los impactos de actuaciones humanas observadas, estudio de las amenazas $\quad \mathrm{X}$ para la biodiversidad en general.

- Partiendo de las especies amenazadas observadas en las salidas, reflexionar sobre la ne- $\quad$ X cesidad de su protección y consolidar los conceptos de endemismo, iberoafricanismo, especie autóctona, especie alóctona...

- Propuesta individual-por equipos-grupo clase de medidas para conservar la biodiversi- $\quad$ X dad, que puede acabar en la elaboración de presentaciones, folletos informativos o actuaciones directas.

Los 5 reinos

- Taxones y nombres científicos de algunos de los seres vivos observados en el entorno.

- Utilización de ejemplos del entorno para la introducción de la mayoría de grupos de seres X vivos (algas, hongos, plantas, invertebrados, vertebrados...) y algunas de sus característi- $\quad \mathrm{X}$ cas principales.

Los ecosistemas

- Análisis de diferencias entre ecosistemas acuáticos y terrestres.

- Realización de informes las características de biotopos y biocenosis observadas en las salidas.

- Utilización de los listados de seres vivos observados para representar redes tróficas.

- Análisis de relaciones intra e interespecíficas observadas.

$\mathrm{X}$

$\mathrm{X}$

$\mathrm{X}$

$\mathrm{X}$

$X$

$X$

\section{$\mathrm{X}$}

- Representación de flujos de materia y energía en las zonas visitadas

Muchas actividades son interdisciplinares, e incluso internivelares, no obstante se ha considerado que distribuirlas por materias, bloques de contenidos y niveles facilitaría la comprensión de la propuesta y su relación con el curriculum. Evidentemente no hay que entender esta distribución como algo rígido. De hecho, la misma no ha coincidido siempre con la distribución real, siendo frecuente el abordar algunas actividades en materias diferentes a las expuestas o abordar la misma actividad en varias materias al mismo tiempo. Durante la realización de los itinerarios, obviamente, se acentúa este carácter interdisciplinar, que no es entorpecido por la habitual estructuración temporal y espacial de las clases y el profesorado. Obviamente, para trabajar de este modo la coordinación entre el profesorado participante es imprescindible. Ésta ha sido estrecha entre los dos profesores que 
suscriben este artículo, contando con colaboraciones puntuales de otros docentes. Sin embargo, como ya se indicó, el profesorado de Ciencias Sociales cambia cada año, lo que ha hecho casi imposible esta coordinación, por lo que, la mayoría de las veces, las actividades de esta materia que aparecen en las tablas, han sido realizadas en las clases de otra materia.

Tabla 5

Test $t$ de medias de las variables de intervalo y de razón

\begin{tabular}{|c|c|c|c|c|c|c|}
\hline \multicolumn{2}{|r|}{ Variable } & Momento & $\begin{array}{l}\mathrm{N}^{\mathrm{o}} \text { de } \\
\text { casos }\end{array}$ & $M$ & $S D$ & $\begin{array}{l}\text { Error estándar } \\
\text { de la media }\end{array}$ \\
\hline \multirow{2}{*}{\multicolumn{2}{|c|}{$\begin{array}{c}\text { ¿Practicarías senderismo en tu tiempo libre } \\
\text { si pudieras? }\end{array}$}} & Post-test & 17 & 3.2353 & 0.9034 & 0.2191 \\
\hline & & Pre-test & 17 & 2.8824 & 1.0537 & 0.2556 \\
\hline T de Student & Grados c & Grados de libertad & 32 & \multicolumn{2}{|c|}{ Significación (2 colas) } & $p=0.3023$ \\
\hline \multicolumn{2}{|r|}{ Variable } & Momento & $\begin{array}{l}\mathrm{N}^{\mathrm{o}} \text { de } \\
\text { casos }\end{array}$ & $M$ & $S D$ & $\begin{array}{l}\text { Error estándar } \\
\text { de la media }\end{array}$ \\
\hline \multirow{2}{*}{\multicolumn{2}{|c|}{$\begin{array}{c}\text { Enumera las especies animales que crees } \\
\text { que pueden verse en el entorno de } \\
\text { Guazamara. }\end{array}$}} & Post-test & 17 & 7.4706 & 5.0264 & 1.2191 \\
\hline & & Pre-test & 17 & 4.5882 & 3.8900 & 0.9435 \\
\hline T de Student & Grados c & Grados de libertad & 32 & \multicolumn{2}{|c|}{ Significación (2 colas) } & $p=0.0707$ \\
\hline \multicolumn{2}{|r|}{ Variable } & Momento & $\begin{array}{l}\mathrm{N}^{\mathrm{o}} \text { de } \\
\text { casos }\end{array}$ & $M$ & $S D$ & $\begin{array}{l}\text { Error estándar } \\
\text { de la media }\end{array}$ \\
\hline \multirow{2}{*}{\multicolumn{2}{|c|}{$\begin{array}{c}\text { Enumera las todas las especies de plantas } \\
\text { silvestres de nuestro entorno que } \\
\text { recuerdes. }\end{array}$}} & Post-test & 17 & 9.1765 & 4.9401 & 1.1981 \\
\hline & & Pre-test & 17 & 2.7647 & 2.1074 & 0.5111 \\
\hline T de Student & Grados c & Grados de libertad & 32 & \multicolumn{2}{|c|}{ Significación (2 colas) } & $p<0.0000$ \\
\hline \multicolumn{2}{|r|}{ Variable } & Momento & $\begin{array}{l}\mathrm{N}^{\mathrm{o}} \text { de } \\
\text { casos }\end{array}$ & $M$ & $S D$ & $\begin{array}{l}\text { Error estándar } \\
\text { de la media }\end{array}$ \\
\hline \multirow{2}{*}{\multicolumn{2}{|c|}{$\begin{array}{l}\text { La naturaleza del entorno de Guazamara } \\
\text { me parece... }\end{array}$}} & Post-test & 17 & 3.0588 & 0.7475 & 0.1813 \\
\hline & & Pre-test & 17 & 2.4706 & 0.7998 & 0.1940 \\
\hline T de Student & Grados c & Grados de libertad & 32 & \multicolumn{2}{|c|}{ Significación (2 colas) } & $p=0.0340$ \\
\hline \multicolumn{2}{|r|}{ Variable } & Momento & $\begin{array}{l}\mathrm{N}^{\mathrm{o}} \text { de } \\
\text { casos }\end{array}$ & $M$ & $S D$ & $\begin{array}{l}\text { Error estándar } \\
\text { de la media }\end{array}$ \\
\hline \multirow{2}{*}{\multicolumn{2}{|c|}{$\begin{array}{c}\text { El paisaje alrededor de Guazamara me } \\
\text { parece ... }\end{array}$}} & Post-test & 17 & 3.1176 & 0.6966 & 0.1690 \\
\hline & & Pre-test & 17 & 2.4706 & 0.5145 & 0.1248 \\
\hline T de Student & Grados c & Grados de libertad & 32 & \multicolumn{2}{|c|}{ Significación (2 colas) } & $p=0.0042$ \\
\hline
\end{tabular}

\section{6.- EVALUACIÓN, RESULTADOS, CONCLUSIONES Y REPERCUSIONES PARA LA CO- MUNIDAD EDUCATIVA}

El programa se ha retroalimentado cada curso en función de los resultados obtenidos y las dificultades encontradas. La evaluación del grado de adquisición de los contenidos por parte del alumnado se ha llevado a cabo a través de pruebas realizadas en cada una de las materias. En 2008-09 decidimos pasar al alumnado de $2^{\circ}$ de ESO un sencillo cuestionario, independiente de las pruebas de cada materia, que nos informara sobre el grado de consecución de los objetivos del programa en su globalidad. En el curso 2009-10 repetimos la operación con el alumnado de $1^{\circ}$ de ESO, y sometimos las respuestas a un análisis más riguroso que exponemos a continuación. 
Vuelta al Cerro de Guazamara-PIV Conocimiento de la flora y paisajes semíríridos

\section{SE BUSCA}

Caralluma europaea. Alias: CHUMBERILIO DE LOBO

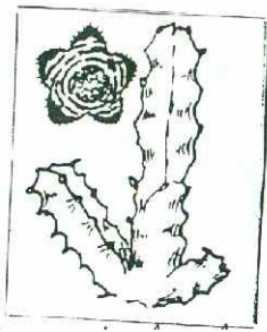

Se suele esconder bajo las rocas u otras plantas en busca de humedad

\section{RECOMPENSA}

El privilegio de contemplar un raro ejemplar: la única planta europea con forma de cactus

Figura 9. Actividad lúdica sobre plantas

\section{- Método}

La técnica utilizada fue la del pretest-postest, pasando el mismo cuestionario (cuyas preguntas pueden verse en las fig, 11 y 12) antes de la realización de la mayoría de las actividades y después, para comprobar los progresos. Este cuestionario se pasó a 8 alumos/as de $2^{\circ}$ de ESO y 9 de $1^{\circ}$ de ESO. Las cuestiones que pretendían medir los conocimientos del alumnado han sido tratadas como variables nominales; para medir la valoración del paisaje y la naturaleza, así como la predisposición a practicar senderismo, se han utilizado escalas tipo Lickert, considerándolas variables de intervalo o mixtas (Santasmases 2009); y las utilizadas para comprobar el número de especies que conocía el alumnado se han tratado como variables de razón. Con las variables de intervalo y de razón, se ha realizado una tabulación cruzada de valores medios y un test $t$ de medias, calculando la $\mathrm{T}$ de Student. Para analizar el resto de cuestiones (variables nominales), se ha realizado una tabulación cruzada de frecuencias.

\section{PARECE UN CASTILLO PERO NO LO ES...}

Se trata de una noria de tiro. Completa el dibujo con todo lo que tendría cuanto estaba en funcionamiento:

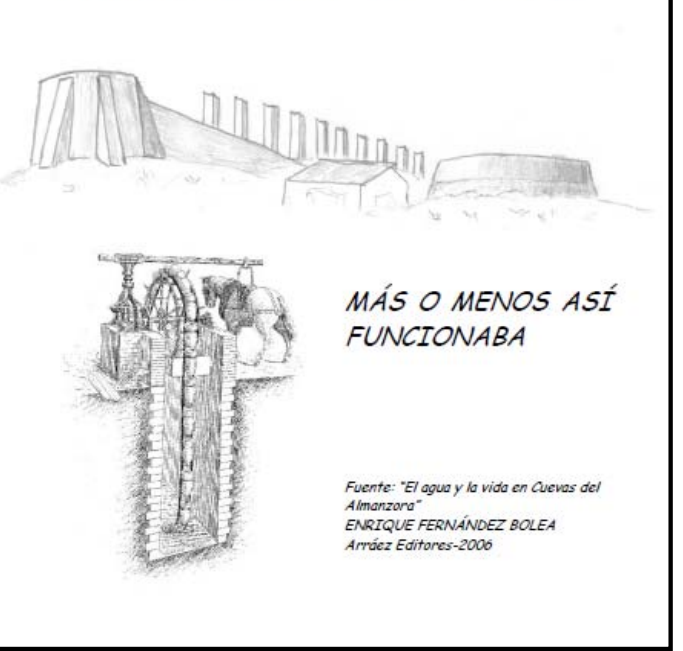

Figura 10. Elementos etnográficos
GRÁFICAS DE LA TABULACIÓN CRUZADA DE VALORES MEDIOS

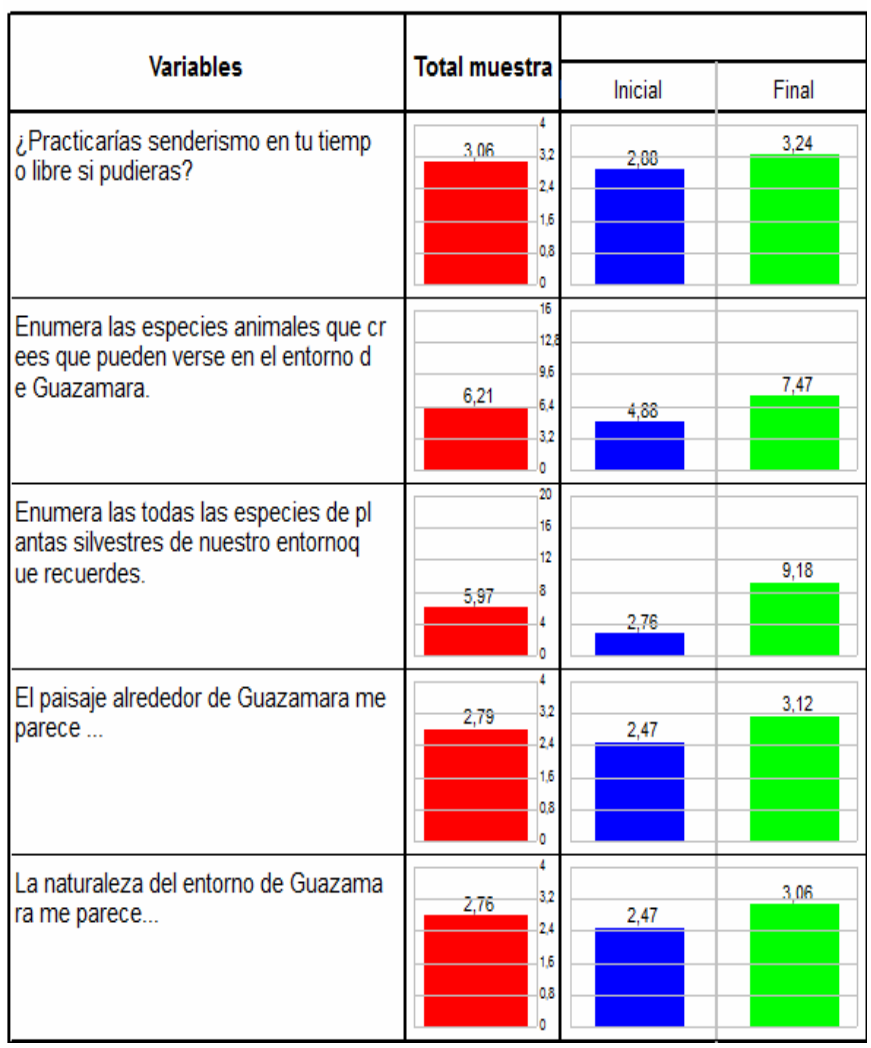

Figura 11.-Gráfica de la tabulación cruzada de valores medios de las variables de intervalo y de razón. 

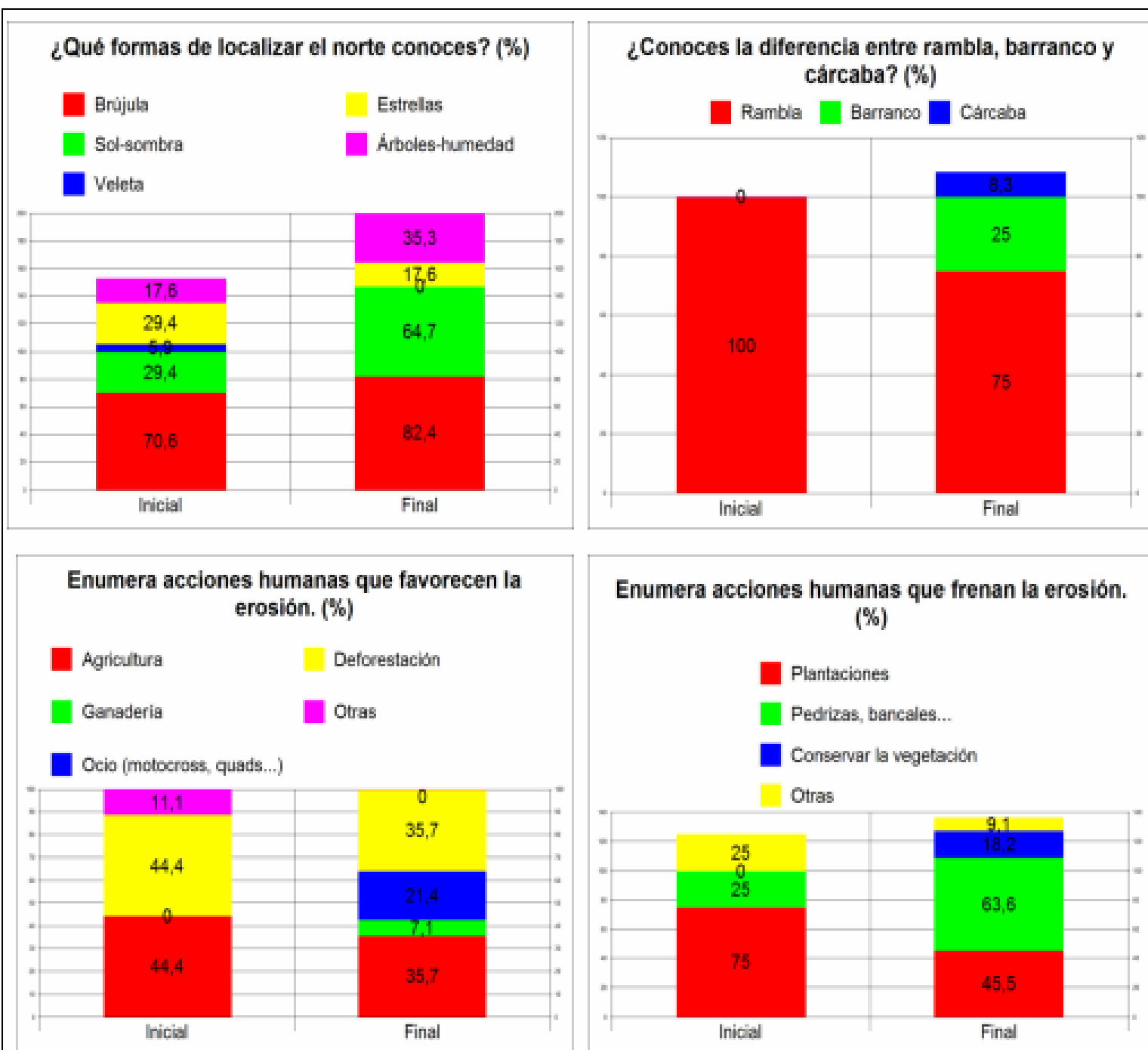

\section{Enumera acciones humanas que frenan la erosión.}

$(\%)$
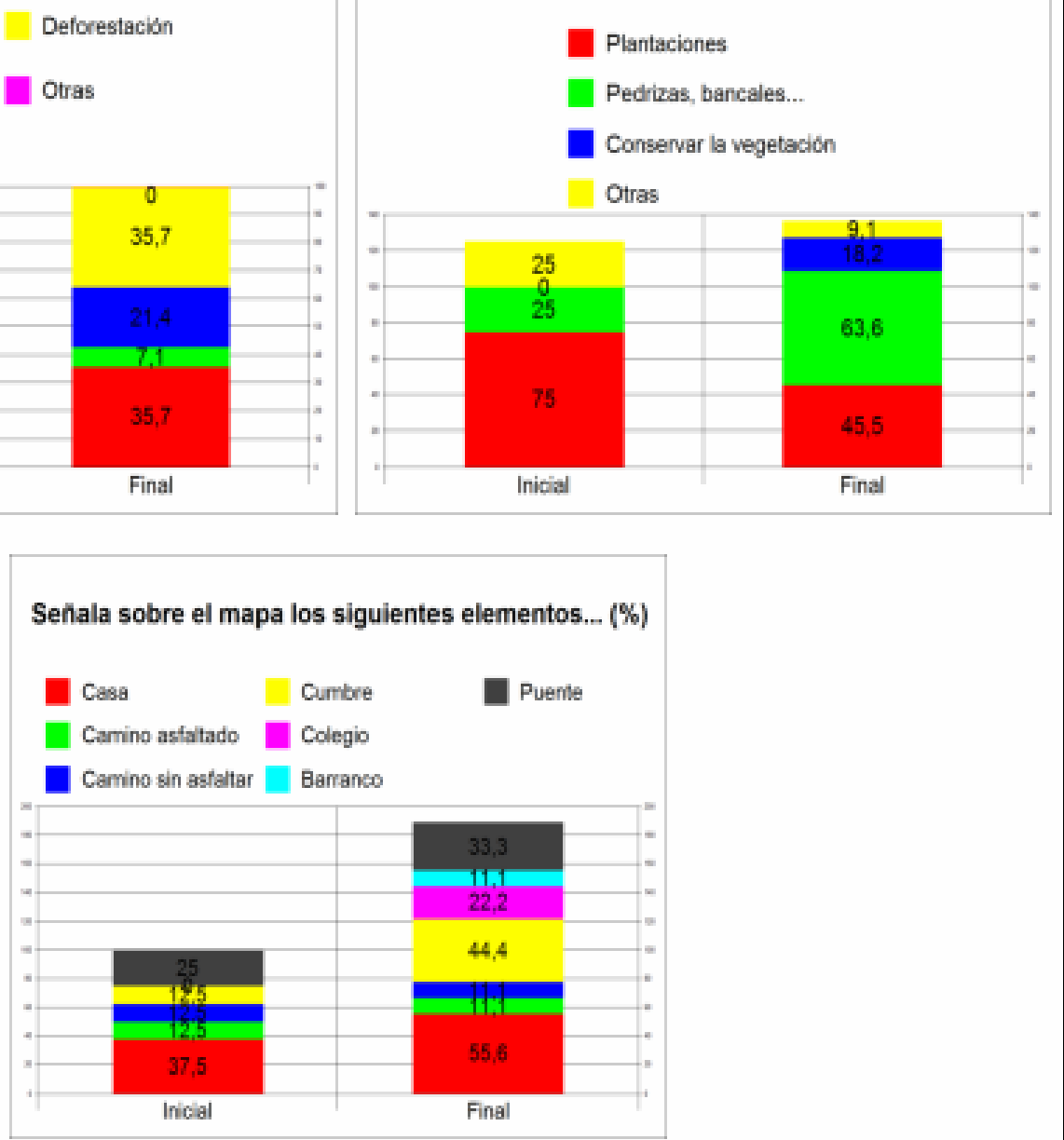

Figura 12.- Gráficas apiladas de la tabulación de frecuencias de las variables nominales. 


\section{- Resultados}

De las gráficas de la tabulación cruzada de valores medios (Fig. 11) se desprende que en todas hubo mejoras. El alumnado muestra una mayor predisposición a practicar senderismo, es capaz de nombrar más especies animales y vegetales, valora mejor el paisaje de su entorno y lo considera más interesante desde el punto de vista natural. Observamos que estas diferencias son estadísticamente significativas, con un nivel de confianza superior al 95\%, en lo que se refiere al conocimiento de la flora y la valoración del paisaje y de la naturaleza (Tabla 5). En cuanto al resto de las cuestiones, relativas a orientación, elementos paisajísticos, acciones humanas e interpretación de mapas, en general se produce un incremento del alumnado que responde a estas cuestiones y sus respuestas son más diversas, destacando el considerable aumento de alumnado capaz de localizar diversos elementos en un mapa topográfico (Figura 12).

\section{- Conclusiones}

A la vista de estos resultados, parece evidente que el programa es eficaz en la consecución de los objetivos que se plantea. Podemos concluir que existen indicios claros de que los itinerarios didácticos de calidad, junto a un adecuado diseño de todas las actividades previas y posteriores de carácter interdisciplinar que éstos pueden generar, son efectivos para el desarrollo del curriculum, las competencias básicas, la valoración del entorno inmediato y las actitudes proambientales. No obstante estos resultados deberían ser refrendados por una investigación más amplia que incluyera un mayor número de sujetos.

Al margen de cuestionarios y pruebas, hay una serie de observaciones que nos aportan una valiosa información complementaria. Como el hecho de que algunos grupos de alumnos y alumnas hayan decidido, de forma espontánea, organizar actividades de senderismo por su cuenta. No sabemos que influencia ha tenido esto en que los habitantes de Guazamara y su entorno sean los más participativos en las actividades de senderismo que organiza el Ayuntamiento de Cuevas, o que en la localidad se haya constituido una asociación de aficionados a la bicicleta de montaña. En cualquier caso las actividades del colegio pueden animar al alumnado a integrarse en estos grupos.

También llama la atención el hecho de que parte del alumnado haga uso de terminología (autóctono, endemismo, erosión...) y nombres de especies (incluso algunos científicos) aprendidos en las excursiones. Todos saben, por ejemplo, lo que es un chumberillo de lobo (Caralluma europea) o un azufaifo (Zicifus lotus). Esto, puede contribuir, de forma directa o indirecta, a que el resto de la comunidad educativa mejore su conocimiento y valoración de lo que siempre han considerado "matojos" sin importancia. De hecho un vecino ha recopilado una considerable colección de fotografías de flora autóctona. Sorprende a la población local el que alumnado y docentes recorran estos "secarrales" para su estudio, lo que hace a algunos replantearse su concepción sobre este entorno.

A pesar de lo indicado anteriormente, hemos observado que el alumnado suele mostrar bastantes dificultades cuando, en las pruebas de evaluación de Ciencias Naturales, se les pide que describan ecosistemas reales con ayuda del cuaderno de campo, lo que puede deberse, en parte, a la falta de hábitos de trabajo no basados en el libro de texto.

También para los docentes ha resultado positivo este proceso. Hemos descubierto la gran utilidad de los itinerarios como recurso y hemos aprendido a utilizarlos para motivar, introducir, desarrollar o complementar una parte importante de nuestras programaciones. Al mismo tiempo, ha aumentado nuestro conocimiento del entorno y, cuantas más veces repetimos un itinerario, más elementos nuevos de interés encontramos. Incluso parte del profesorado, que no participa en el programa, termina contagiándose de este interés por el medio natural.

\section{7.- REFERENCIAS}

Alarcón Martínez, J., Cañadas Martínez, F., Cazorla Núñez, M. J., Muñoz Molina, M., y López Hernández, S. (2003). Itinerarios por el Bajo Almanzora. Almería: Junta de Andalucía.

Banqueri Forns-Samsó, E. (2006). Orientación y mapas. Barcelona: Parramon. 
Beas Jiménez, M., Rodríguez Prados, F., y Martínez Moreno, A. (2009). El entorno natural y las actividades físicas en el medio natural como base para un proyecto educativo multidisciplinar. Espiral. Cuadernos del Profesorado [en línea], 2(4), 56-65. Disponible en: http://www.cepcuevasolula.es/espiral/articulos/ESPIRAL_VOL_2_N_4_ART_6.pdf [Consulta: 2012, 3 de junio].

Casterad, R., Guillén, S., y Lapetra, J. (2000). Actividades en la naturaleza. Barcelona: Inde.

Costa Canovas, P. J., y Giménez Martínez, L. (1997). Orientación en la Naturaleza. Manual básico de iniciación. Murcia: ASEEF.

García Díaz, J. E. (2002). Los problemas de la Educación Ambiental ¿es posible una Educación Ambiental integradora?. Investigación en la Escuela [en línea], 46, 5-26. Disponible en: http://www.investigacionenlaescuela.es/articulos/46/R46_1.pdf [Consulta: 2012, 20 de diciembre].

Gilpérez Fraile, L. (1997). Plano y Brújula. Manual de interpretación de planos y orientación en la Naturaleza. Madrid: Penthalon Ediciones.

Gómez López, A. (2008). El senderismo. Actividad física organizada en el medio natural. Wanceulen E. F. Digital [en línea], 4, 131-141. Disponible en : http://rabida.uhu.es/dspace/bitstream/handle/10272/2166/b15349822.pdf?sequenc [Consulta: 2012, 24 de diciembre].

Iglesias Cueto, J. A. (2005). Fichero de actividades en la Naturaleza. Inde Publicaciones.

Jiménez, M. J., y Laliena, L. (1992). Transversales: Educación Ambiental. Madrid: MEC.

López de Haro, F. et al. (2009). Las Cuarenta Principales. Guía de Plantas del Tortujardín. Murcia: Natursport.

López de Haro, F., Martínez Cano, A., y Tomás Ruiz, F. (2002). El Levante Almeriense, 20 excursiones a pie y en bici. Murcia: Natursport.

Martínez González, R. A. (2007). La investigación en la práctica educativa: Guía metodológica de investigación para el diagnóstico y evaluación en los centros docentes. Madrid: Ministerio de Educación y Ciencia-C. I. D. E.

Martínez López, F., J., y García Soriano, A. J. (2008). Itinerarios didácticos por Fuente Álamo (Murcia), una estrategia educativa de innovación en el proceso de enseñanza-aprendizaje en educación secundaria. Espiral. Cuadernos del Profesorado [en línea], 1(1), 1.9. Disponible en : http://www.cepcuevasolula.es/espiral/articulos/ESPIRAL_VOL_1_N_1_ART_4.pdf. [Consulta: 2012, 3 de junio].

Mota, J., Cabello, J., Cerrillo, M. I., y Rodríguez Tamayo, M. L. (eds.) (2004). Subdesiertos de Almería naturaleza de cine. Consejería de Medio Ambiente. Junta de Andalucía.

Muñoz Muñoz, J. A., y Ruiz García, A. (2002). Itinerario por Cabo de Gata y Campos de Nijar. Almería: Consejería de Educación. Junta de Andalucía.

Consejería de Medio Ambiente (2012). Patrimonio Geológico y Geodiversidad. Paraje Natural Desierto de Tabernas. Junta de Andalucía

Consejería de Medio Ambiente (2012). Patrimonio Geológico y Geodiversidad. Paraje Natural Karst en Yesos de Sorbas. Junta de Andalucía.

Pérez Casas, C. (2005). Análisis de una estrategia didáctica para el desarrollo de la capacitación para la acción en favor del medio en alumnos de secundaria. Tesis doctoral. Departamento de Didáctica de las Ciencias Experimentales. Universidad de Granada.

Pila Teleña, A. (1988). Educación Física-deportiva. Enseñanza y aprendizaje. Madrid: Editorial Pila Teleña.

Pino Quílez. M. (1997). Actividades Físico Deportivas en la Naturaleza. Madrid: Gimnos.

Romero Ramos, O., Merino Marbán, R., y Fernández Rodríguez, E. (2006). La multidisciplinariedad y las actividades educativo-recreativas en la naturaleza. Aula Verde, (30), 24-25.

Santesmases Mestre, M. (2009). DYANNE versión 4. Diseño y análisis de encuestas en investigación social y de mercados. Madrid: Ediciones Pirámide.

Torres Guerrero, J, Rivera García, E., Arráez Martínez, J. M., Merino Díaz, J. A., y López Sánchez, J. M. (1994). Las actividades físicas organizadas en educación Primaria. Granada: Imprenta Rosillo’́s.

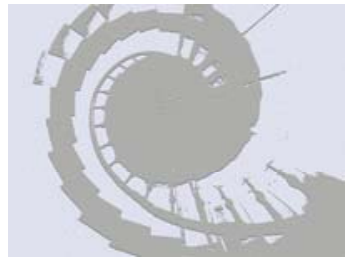

